BULLETIN Bulletin hispanique

HISPANIQUE Université Michel de Montaigne Bordeaux

122-2 | 2020

L'épithalame en Espagne

\title{
Nuptialia: hacia una cartografía de la escritura epitalámica en España
}

Jesús Ponce Cárdenas

\section{(2) OpenEdition}

1 Journals

\section{Edición electrónica}

URL: http://journals.openedition.org/bulletinhispanique/11091

DOI: 10.4000/bulletinhispanique. 11091

ISBN: 1775-3821

ISSN: 1775-3821

Editor

Presses universitaires de Bordeaux

Edición impresa

Fecha de publicación: 20 diciembre 2020

Paginación: 399-406

ISBN: 979-10-300-0606-3

ISSN: 0007-4640

\section{Referencia electrónica}

Jesús Ponce Cárdenas, «Nuptialia: hacia una cartografía de la escritura epitalámica en España», Bulletin hispanique [En línea], 122-2 | 2020, Publicado el 14 diciembre 2020, consultado el 19 enero 2021. URL: http://journals.openedition.org/bulletinhispanique/11091 ; DOI: https://doi.org/10.4000/ bulletinhispanique.11091 


\section{Nuptialia: hacia una cartografía de la escritura epitalámica en España*}

$\mathrm{P}$ ese al notable avance que se ha producido en el conocimiento de la poesía del Siglo de Oro durante las últimas décadas, existen todavía algunas secciones de la misma que no han sido objeto de exploración sistemática. Por espigar tan solo dos áreas especialmente preteridas, quisiera mencionar ahora la escritura laudatoria y la lírica sacra. En efecto, buena parte de la crítica ha evitado el estudio de tan amplios conjuntos aduciendo razones peregrinas. Los prejuicios más asentados insisten en que dichos poemas obedecerían a un deleznable espíritu de lisonja y que además se sustentarían en valores (sociales o espirituales) inasumibles por la cultura post-moderna... Considerando en bloque ese variado acervo, se ha convertido asimismo en un lugar común considerar que se trata de textos de escasa calidad literaria ${ }^{1}$. Toda justificación era válida para rehuir una tarea tan amplia como apasionante: ordenar dos de las secciones más ricas de la literatura áureo secular, cribar un cuantioso conjunto de poemas de calidad dispar, editar algunas piezas relevantes, ofrecer análisis detallados de algunos de los ejemplares más notables del género.

Para paliar algo tan lastimosa situación, a lo largo del trienio 2016-2018, un equipo internacional de investigadores acometió la tarea de recuperar críticamente el interesante legado de un género muy poco atendido: el panegírico en verso. Dicho esfuerzo colectivo ha dado varios frutos, entre los que cabe destacar el volumen titulado Las Artes del Elogio y un monográfico

* El presente conjunto de estudios se inscribe en el marco del Proyecto de Investigación «Hibridismo y Elogio en la España Áurea» (HELEA) PGC2018-095206-B-I00, financiado por el Ministerio de Ciencia e Innovación y por el Fondo Europeo de Desarrollo Regional (FEDER).

1. Con suma perspicacia Antonio Carreira había denunciado en un conocido trabajo cómo "el concepto de poesía de circunstancias» a menudo "se convierte en prejuicio». En dichas páginas ponía además el énfasis en la equivocada actitud de suspicacia con la que suele mirarse este tipo de composiciones, ya que «en tal tipo de poesía se encuentran auténticas joyas». Remito a «Poesía de circunstancias: epitafios a la duquesa de Lerma (1603)», Poéticas de la Metamorfosis. Tradición clásica, Siglo de Oro y Modernidad, Málaga, Universidad de Málaga-Universidad de Almería, 2002, p. 321-342 (p. 323). 
en la revista Criticón, además de la edición de varias piezas laudatorias de singular valor ${ }^{2}$. En clara continuidad con el Proyecto ARELPH, durante el cuadrienio 2019-2022, uno de los objetivos principales del Proyecto de Investigación "Hibridismo y Elogio en la España áurea» (HELEA) es abordar el estudio sistemático de la poesía nupcial del Siglo de Oro, atendiendo a los valores estéticos de estas composiciones, identificando los modelos (clásicos, neolatinos o italianos) que sustentan la imitatio, profundizando en el estudio de las prácticas de mecenazgo o 'patrocinio cultural' que a través de tales piezas laudatorias se evidencian... Uno de los primeros logros de ese esfuerzo compartido por especialistas de diferentes universidades europeas es el presente monográfico.

\section{La poesía epitalámica en la EdAd de Oro: temas y PROBlemas}

Al definir la voz «epitalamio», Bartolomé Jiménez Patón proporcionaba en 1621 una noticia -tan sintética como relevante- sobre este género epidíctico:

Epitalamio es poesía hecha a la celebridad de las bodas y casamientos de algunos, como se hallan en Catulo, Claudiano y Ausonio. En nuestro español hay muchos en papeles no impresos ${ }^{3}$.

En apenas dos líneas, esta definición del autor de la Elocuencia española en arte lograba iluminar tres aspectos capitales de la escritura nupcial del Siglo de Oro. En primer lugar destaca el aspecto celebrativo, que la identifica como poesía de circunstancias y la ancla a un determinado suceso histórico. Seguidamente, al igual que hiciera Giulio Cesare Scaligero en los Poetices Libri Septem, Jiménez Patón subraya cuáles podían ser los tres modelos clásicos más aptos para la imitatio. A nadie le sorprenderá que en ese punto preciso concurran los nombres de Catulo y Claudiano, aunque probablemente llame la atención de algunos la referencia al Cento nuptialis ausoniano, texto bien conocido por su carácter juguetón y subido de tono, verdadero patchwork hecho con retales virgilianos ${ }^{4}$. Por último, el tratadista aporta una sintética valoración sobre la relativa abundancia de tales escritos en lengua vernácula («en español hay muchos») y, lo que resulta aún más interesante, insiste en un detalle «material»

2. Jesús Ponce Cárdenas (ed.), Las Artes del Elogio: Estudios sobre el Panegirico, Valladolid, Universidad de Valladolid, 2017. Jesús Ponce Cárdenas (coord.), El Panegírico en el Siglo de Oro, en Criticón, 2018. Sobre los poemas recuperados, pueden citarse aquí los textos de Calderón de la Barca, Panegírico al Almirante de Castilla, ed. J. Ignacio Díez Fernández, Madrid, Giardini di Bomarzo, 2018. Miguel Silveira, Parténope ovante, ed. Carlos Primo, Madrid, Giardini di Bomarzo, 2018. Gabriel de Corral, Panegírico a Taddeo Barberini, ed. Jesús Ponce Cárdenas, Madrid, Giardini di Bomarzo, 2018. García de Salcedo Coronel, Retrato Panegírico al conde duque de Olivares, ed. Jesús Ponce Cárdenas, Madrid, Giardini di Bomarzo, 2018.

3. Elocuencia Española en arte, Barcelona, Puvill, 1993, p. 433-434.

4. Sobre la familia (o agrupación heterogénea) de textos nupciales grecolatinos y su proyección en la poética áureo-secular, puede verse el artículo de Mercedes Blanco integrado en este monográfico. 
de la circulación de unos poemas que a menudo se difundieron «en papeles no impresoss.

En esencia, las poesías epitalámicas se presentan -al igual que los restantes textos líricos de la época- bajo tres formas posibles: en copia manuscrita (de localización más o menos recóndita); editadas en sueltas o plaquettes, como pliegos breves; insertas en una obra impresa (ya sea esta una colección de Rimas de un mismo autor, ya dentro de un libro per nozze compuesto por diversos ingenios, ya en un tomo misceláneo o prosímetro). El caso de los textos impresos recogidos en volumen pone en juego otro aspecto destacable, ya que pueden mediar muchos años de distancia entre la fecha de composición del poema nupcial y su publicación en libro, circunstancia esta última que afecta a la perdurabilidad del texto, garantizando la misma a través de una suerte de difusión masiva ${ }^{6}$.

Como han demostrado los modélicos estudios de Antonio Serrano Cueto, la boga de la poesía epitalámica en la península ibérica se inició entre los autores neolatinos a finales del siglo XV (Elio Antonio de Nebrija) y se prolongó durante toda la centuria siguiente (Martín Ivarra, 1514; Antonio Agustín, 1540; Petreyo, $1543 \ldots)^{7}$. Desde el punto de vista de la aclimatación del género laudatorio en la letras vernáculas, los comienzos de la escritura nupcial remiten, ineludiblemente, a la obra de Garcilaso, ya que el poeta toledano insertó en la Égloga segunda (vv. 1401-1418) un quintaesenciado pasaje en alabanza de las bodas de don Fernando Álvarez de Toledo y doña María Enríquez, duques

5. Este último matiz se antoja relevante a la hora de calibrar la pervivencia de este cauce epidíctico, del que aún no se ha abordado la necesaria catalogación. Jiménez Patón parecía subrayar así la difusión de los poemas de elogio a través de copias manuscritas, lo que en principio justificaría algo la escasez - tan aparente como relativa- de composiciones que han llegado a nuestros días.

6. En tanto poesía de circunstancias, los textos nupciales del Siglo de Oro se concibieron para ensalzar unos esponsales concretos (ya regios, ya aristocráticos, ya familiares). Por ese motivo, establecer la identidad de los nobles contrayentes e identificar la fecha concreta de celebración de los desposorios resultan dos tareas esenciales a la hora de fijar la fecha de composición de aquellos versos laudatorios. Por ese motivo, en una labor impulsada por cierto rigor histórico y cultural (relacionado con el mecenazgo o el patrocinio aristocrático), se antoja obligado sondear genealogías, rastrear diferentes crónicas cortesanas, consultar documentación de archivos nobiliarios... Sólo a través de ese tipo de pesquisa previa se consigue establecer una datación tan precisa como sea posible de los epitalamios. En este punto radica una de las principales fallas de la tesis doctoral de Thomas George Deveny: The Epithalamium in the Spanish Renaissance, Chapel Hill, University of North Carolina, 1978. Si bien este trabajo fue pionero al interesarse en el género laudatorio, desafortunadamente la mayor parte de los carmina nuptialia analizados por el profesor Deveny carecen de atribución temporal, lo que arroja cierta sombra sobre su investigación.

7. Es de obligada consulta la excelsa monografía que ha publicado en fechas recientes Antonio Serrano Cueto: El epitalamio neolatino. Poesía y matrimonio en Europa (siglos XV-XVI), Alcañiz-Lisboa, Instituto de Estudios Humanísticos-Universidad de Lisboa, 2019. En torno a la aportación específica del Humanismo español a este género neolatino, véase la reflexión del profesor Serrano Cueto recogida en este mismo número. 
de Alba (celebradas en 1529) ${ }^{8}$. Otro testimonio temprano es el que ofrecía Francisco de Aldana, que modeló algunos motivos nupciales desde la óptica de un personaje rústico en las Octavas a lo pastoral hechas recitar en unos desposorios de un hermano suyo (hacia 1564).

Entre las postrimerías del Quinientos y los primeros años del siglo XVII no parece que fueran muy numerosos los intentos de revivir en castellano el antiguo género laudatorio. Dentro de ese marco temporal pueden destacarse, empero, varias piezas aisladas que ofrecen algún interés, como la Canción al duque de Pastrana sobre su casamiento, compuesta por Juan Rufo en 1584. Por otro lado, en el volumen titulado Discursos, epistolas y epigramas de Artemidoro (Zaragoza, Angelo Tabano, 1605), Andrés Rey de Artieda recogía hasta tres poemas nupciales compuestos en octavas: el Discurso al casamiento del duque de Alburquerque, el Epitalamio a los marqueses de la Bañeza y las estancias Al casamiento del ilustrísimo marqués de Cuéllar. Otro ingenio bien conectado en la corte, Lupercio Leonardo de Argensola, tomó la pluma en 1608 para exaltar el enlace de María Francisca Climente Enríquez y Juan Funes de Villalpando y Ariño ${ }^{9}$. En 1612 Lope de Vega quiso rendir homenaje al heredero de uno de sus principales mecenas, el duque de Alba, con los sextetos lira de la canción En las bodas de don Fernando Jacinto de Toledo, duque de Huéscar, y doña Antonia Enríquez, marquesa de Villanueva ${ }^{10}$.

Frente a los ejemplos -no demasiado numerosos- de composiciones nupciales redactadas entre 1530 y la primera década del siglo XVII, a partir de 1615 comenzó una boga lírica que se extendió de forma imparable hasta la centuria siguiente. Ese fenómeno creciente fue constatado ya por Thomas George Deveny, quien sostuvo en su tesis doctoral que el acto de "comisionar» a los poetas para "conmemorar esponsales» en verso llegó a convertirse en «una costumbre de moda entre la nobleza hispana» durante un arco temporal que se extendería entre 1615 y $1640^{11}$. Ahora bien, para comprender cuáles pudieron ser las causas de la creciente floración del epitalamio en España a partir de la segunda década del siglo XVII, conviene tener presentes dos hechos decisivos: la imparable difusión manuscrita de las Soledades de Góngora desde el bienio 1613-1614 y el éxito obtenido por la colección de los Epithalami de Giovan Battista Marino, publicados simultáneamente en París y en Venecia

8. Entre el conjunto de estudios que integran el presente monográfico, se ocupa de analizar el pasaje garcilasiano en relación con la poesía nupcial partenopea Roland Béhar.

9. Se ocupa de dicha alabanza nupcial J. Ignacio Díez en un artículo de este monográfico.

10. El poema vio la luz de la imprenta nueve ańos más tarde, ya que fue recogido en el volumen de La Filomena. Puede leerse ahora el texto en Obras poéticas, Barcelona, Planeta, 1989, p. 837-839. Dedicó un importante estudio a dicha composición Patricia Campana en su tesis doctoral, dirigida por Alberto Blecua: La Filomena de Lope de Vega, Barcelona, Universitat Autónoma, 1998, p. 543-549. Puede verse también Thomas George Deveny, «Lope de Vega y el epitalamio", Hispanófila, 88, 1986, p. 1-25.

11. Thomas George Deveny, The Epithalamium in the Spanish Renaissance, Chapel Hill, University of North Carolina, 1978, p. 216. 
en $1616^{12}$. La sección epitalámica inserta en la inconclusa obra maestra gongorina rivalizaba con los grandes modelos del género (Catulo, Claudiano, Pontano, Torquato Tasso...) y pronto hubo de convertirse en el texto nupcial más imitado del país ${ }^{13}$. Por otro lado, el éxito de las poesie per nozze del cavalier napolitano fue clamoroso en distintas cortes europeas (señaladamente entre Francia e Italia) y por los dominios hispánicos en la península italiana (Lombardía, Sicilia, Cerdeña y el reino de Nápoles). Sin duda, tal circunstancia facilitaría grandemente la llegada de los textos marinianos a la península ibérica aunque, de hecho, todavía se ha de sondear el influjo ejercido por el mayor lírico italiano del Seicento en el campo de la literatura epitalámica española. El interés hispánico por la colección de versos nupciales de Marino pudo acaso verse reforzado por la circunstancia de que aquella raccolta se abría con un ambicioso poema dedicado al matrimonio de Luis XIII con la infanta Ana de Habsburgo: la Francia consolata. Epithalamio nelle nozze delle Maestà Christianissime Lodovico XIII, Rè di Francia, et Anna d'Austria, Primogenita di Spagna ${ }^{14}$.

Las prácticas de la alabanza cortesana que se movilizaron con ocasión de los desposorios regios o aristocráticos conocieron una difusión imparable durante los años finales del reinado de Felipe III (1615-1621) y durante las décadas que Felipe IV (1621-1665) y Carlos II (1665-1700) se mantuvieron en el trono. Poetas de estilo tan variado como Francisco López de Zárate, Gabriel Bocángel, Gabriel de Corral, Anastasio Pantaleón de Ribera, Hernando Manojo de la Corte, Alonso Jéronimo de Salas Barbadillo, Melchor Fernández de León, Sebastián Francisco de Medrano, fray Alonso Remón, Martín Miguel Navarro, José Pellicer de Salas y Tovar, Salvador Jacinto Polo de Medina, Lorenzo de Guerra, García de Salcedo Coronel, Francisco de Trillo y Figueroa, Sebastián de Gadea, Juan de Trillo y Figueroa, Juan de Herbias, Agustín de Salazar y Torres, Diego Francisco de Andosilla y Enríquez, Melchor de Fonseca Almeida, María Nieto de Aragón, Melchor Zapata, Sebastián Ventura de Vergara, Francisco Zapata Pimentel, Miguel de Barrios, José Nicolás Pérez de Urzanqui, Francisco Bueno constituyen parte de la pléyade de ingenios secentistas que contribuyeron con sus versos a la extensión de la escritura epitalámica en nuestras letras ${ }^{15}$.

12. Danielle Boillet, «Les Epitalami de Giovan Battista Marino: le livre et sa fabrique», Danielle Boillet y Liliana Grassi (eds.), Forme e occasioni dell'encomio tra Cinque e Seicento, Lucca, Maria Pacini Fazzi Editore, 2011, p. 181-212. Emilio Russo, «Sulle Amorose Tenerezze del Marino: tra Epitalami ed Adone», Italique, XVII, 2014, p. 143-162.

13. Para la conexión de la sección epitalámica de las Soledades con los modelos neolatinos, véase en este monográfico la contribución de Jesús Ponce Cárdenas.

14. Margaret M. McGowan, Dynastic Marriages 1612-1615. A Celebration of the Habsburg and Bourbon Unions, London, Ashgate Publishing, 2013.

15. En el anexo del elenco de los «Epitalamios impresos entre 1650 y 1750 », Alain Bègue identificaba hasta cincuenta y seis composiciones, compuestas por treinta y un ingenios. «Ven, Himeneo, ven; ven, Himeneo: el epitalamio en las postrimerías del siglo XVII», en A. Bègue (ed.), La poesía epidíctica del Siglo de Oro y sus antecedentes, Vigo, Academia del Hispanismo, 2013, p. 111-165 (en especial, p. 143-151). 
Siguiendo las prácticas de la imitatio y la aemulatio, la composición de poemas nupciales fue igualmente cultivada durante el siglo XVIII y mantuvo parte de su vigencia hasta bien entrado el siglo XIX.

Frente al nivel de conocimiento en torno al epitalamio al que se ha llegado en otras literaturas de ámbito europeo, el caso hispánico resulta llamativo por una razón esencial: las numerosas carencias que presenta. En destacado primer plano hay que mencionar la ausencia de un catálogo fiable que identifique este complejo corpus laudatorio y permita trazar una historia del mismo del modo más exhaustivo posible ${ }^{16}$. Como punto de contraste, baste pensar que para la literatura italiana contamos desde hace décadas con dos voluminosos repertorios bibliográficos dedicados en exclusiva a los libretti per nozze $e^{17}$. Aún más positivo resulta el balance de la literatura neolatina, ya que puede trazarse una detallada panorámica del epitalamio en latín humanístico gracias a un libro de Skirmanté Sarkauskiené, un importante ensayo de Anthony F. D’Elia y, sobre todo, merced a una monografía modélica de Antonio Serrano Cueto, que acaba de ver la luz ${ }^{18}$. También desde el ámbito de la literatura inglesa se han consagrado importantes reflexiones a este legado epidíctico, como prueban los volúmenes de Virginia Tufte y Heather Dubrow ${ }^{19}$.

Para no incurrir en jeremiadas estériles, justo es reconocer cómo a lo largo de los dos últimos decenios un conjunto de asedios ha analizado diferentes aspectos de la literatura epitalámica en España ${ }^{20}$. Dentro de ese grupo es

16. Atendiendo tanto a las composiciones conservadas en manuscritos como a los poemas impresos, una de las tareas principales que, bajo mi dirección, aborda el joven investigador Daniel Mateo Benito en su tesis doctoral es precisamente el establecimiento de un repertorio minucioso de este género epidíctico en los siglos XVI y XVII. Permítaseme, pues, remitir al estudio titulado El epitalamio en el Siglo de Oro: tradición y cambio en un género de alabanza, Madrid, Universidad Complutense, en curso de realización (fecha estimada para la defensa 2022).

17. Olga Pinto, Nuptialia. Saggio di bibliografia delle edizioni per nozze dal 1484 al 1799, Firenze, Olschki, 1971. Giovanna Bosi Maramotti, Le Muse d'Imeneo. Metamorfosi letteraria dei libretti per nozze dal '500 al '900, Ravenna, Edizioni del Girasole, 1995.

18. Anthony F. D'Elia, The Renaissance of Marriage in Fifteenth-Century Italy, CambridgeLondon, Harvard University Press, 2004. Skirmanté Sarkauskiené, Lotyniskasis XVI-XVII amziaus LDK epitalamijas, Kaunas, 2003. Antonio Serrano Cueto, El epitalamio neolatino. Poesía y matrimonio en Europa (siglos XV-XVI), Alcañiz-Lisboa, Instituto de Estudios HumanísticosUniversidad de Lisboa, 2019.

19. Virginia Tufte, The Poetry of Marriage: the Epithalamium in Europe and its development in England, Los Angeles, Tinnon-Brown, 1970. Heather Dubrow, A Happier Eden: the Politics of Marriage in the Stuart Epithalamium, Ithaca, Cornell University Press, 1990.

20. Ante todo, permítase destacar la importancia del conjunto de artículos del profesor Serrano Cueto sobre las composiciones en latín humanístico, publicados entre el año 2003 y el 2015: «La novia remisa y el novio ardiente en el epitalamio latino: una imagen que pervive en el Renacimiento», Cuadernos de Filología Clásica. Estudios latinos, 23, 1, 2003, p. 153-170; «El epitalamio latino (1560) de Diego de Guevara en honor de Felipe II e Isabel de Valois», Calamus Renascens, 9, 2008, p. 245-292; "Las lágrimas de la "nova nupta” en la tradición del epitalamio latino», Minerva, 24, 2011, p. 137-155; «Isabel de Valois como esperanza de paz contra la herejía. Motivos del epitalamio en la Oratio christiana (1560) de Pedro del Frago», Cuadernos de Filología Clásica. Estudios latinos, 31, 2, 2011, p. 311-331; «Hacia un repertorio de la poesía 
obligado citar las aportaciones de Mercedes Blanco ${ }^{21}$, Jesús Ponce Cárdenas ${ }^{22}$, Javier Portús ${ }^{23}$, José Javier Azanza ${ }^{24}$, Inmaculada Osuna ${ }^{25}$, Madoka Tanabe ${ }^{26}$, Inmaculada Rodríguez Moya ${ }^{27}$, Nieves Baranda ${ }^{28}$, Almudena Marín Cobos ${ }^{29}$, Encarnación Sánchez García ${ }^{30}$, Alain Bègue ${ }^{31}$, María Dolores Martos ${ }^{32}$, Anna

nupcial latina de los siglos XV y XVI», Humanismo y pervivencia del mundo clásico. Homenaje al profesor Juan Gil, Alcañiz-Madrid, Instituto de Estudios Humanísticos, CSIC, 2015, p. $1485-1528$.

21. «El toro nupcial de la Soledad primera. Paradigmas y creación simbólica», Góngora o la invención de una lengua, León, Universidad de León, 2012, p. 315-340.

22. "El epitalamio barroco: algunas notas sobre la narratio mítica», Estudios sobre tradición clásica y mitología, Madrid, Ediciones Clásicas, 2003, p. 83-94; «Sobre la praxis poética: consideraciones para una breve historia del epitalamio desde los orígenes hasta el siglo XVII", "De algunas hibridaciones del género epitalámico», "Avatares de la sensualidad clásica: entre la poesía didáctica y el centón nupcial», "Ludunt laeti in amore pares: de milicia amorosa y entorno nupcial en la lírica neolatina», en Evaporar contempla un fuego helado. Género, enunciación lírica y erotismo en una canción gongorina, Málaga, Universidad de Málaga, 2006, p. 63-86, 87-116, 205-226, 227-248; «La variedad culta en Agustín de Salazar y Torres: lectura de tres sonetos y dos epitalamios», Analecta Malacitana, XXXI, 1, 2008, p. 31-59; "Eros nupcial: imágenes de la sensualidad en la poesía epitalámica europea», eHumanista, 15, 2010, p. 176-208; "Entorno bucólico y entorno epitalámico: intersecciones renacentistas", en El tapiz narrativo del Polifemo: eros y elipsis, Barcelona, Universitat Pompeu Fabra, 2010, p. 117-132; "Lasciva abeja al virginal acanto: una imagen sensual en la Soledad primera”, en Patricia Marín Cepeda (ed.), Eros y Logos. Literatura y Erotismo en los siglos XVI y XVII, Berlín, Peter Lang, 2020, en prensa.

23. «Retratos familiares en el Siglo de Oro español», en Ignacio Arellano y Jesús M. Usunáriz, Elmatrimonio en Europa y el mundo hispánico. Siglos XVIy XVII, Madrid, Visor, 2005, p. 257-269.

24. "Símbolos y alegorías matrimoniales en el retrato renacentista y barroco», en Ignacio Arellano y Jesús M. Usunáriz, El matrimonio en Europa y el mundo hispánico. Siglos XVI y XVII, Madrid, Visor, 2005, p. 271-295.

25. «Recepción y creación poética: el ms. 90-V1-9 de la Fundación Bartolomé March y la poesía en Granada a finales del siglo XVII», Criticón, 103-104, 2008, p. 93-117.

26. "Tradición e innovación en el epitalamio de la Primera Soledad», Analecta Malacitana Electrónica, 30, 2011, p. 59-89.

27. "Epitalamios e Himeneos. Iconografía y literatura nupcial en las cortes del Barroco», Imago, 2, 2011, p. 7-24. Inmaculada Rodríguez Moya y Víctor Mínguez Cornelles, Himeneo en la corte. Poder, representación y ceremonia nupcial en el arte y la cultura simbólica, Madrid, C.S.I.C., 2013.

28. «Cantos al sacro epitalamio o sea pliegos poéticos para las tomas de velo. Deslindes preliminares», Bulletin Hispanique, 113, 1, 2011, p. 269-296.

29. Estudio y edición de Francisco de Trillo y Figueroa, Epitalamio en las felicísimas bodas de Francisco Ruiz de Vergara y Ávila, Madrid, Clásicos Hispánicos, 2012.

30. «Ecos gongorinos en la Nápoles del III duque de Alcalá: el Epitalamio de Salcedo Coronel en honor de María Enríquez de Ribera y Luis de Aragón y Moncada», en E. Sánchez García (ed.), Lingua spagnola e cultura ispanica a Napoli fra Rinascimento e Barocco. Testimonianze a stampa, Napoli, Tullio Pironte Editore, 2013, p. 241-272.

31. «Ven, Himeneo, ven; ven, Himeneo: el epitalamio en las postrimerías del siglo XVII», en A. Bègue (ed.), La poesía epidíctica del Siglo de Oro y sus antecedentes, Vigo, Academia del Hispanismo, 2013, p. 111-165.

32. «Panegíricos nupciales a las bodas del IX y X duque de Medina Sidonia: mecenazgo, propaganda y renovación estética», en José Manuel Rico García y Pedro Ruiz Pérez (eds.), El duque de Medina Sidonia: mecenazgo y renovación estética, Huelva, Universidad de Huelva, 2015, p. 289-298. 
García Busquets ${ }^{33}$, Luis Sánchez Laílla ${ }^{34}$ y Alejandro Coroleu ${ }^{35}$. El avance cuantitativo y cualitativo que entrañan estas reflexiones es esencial, aunque todavía quedan muchos trabajos pendientes.

El conjunto de artículos aquí reunido viene, pues, a cubrir un hueco destacado en la bibliografía hispánica, ya que se centra en el análisis de la poesía nupcial desde el Renacimiento hasta la primera mitad del siglo XVIII, atendiendo tanto a las composiciones neolatinas como a los poemas redactados en lengua vernácula. La conformación de un ambicioso panorama crítico permitirá a los investigadores interesados en el desarrollo de la materia epitalámica hacerse una idea cabal sobre la fortuna de este género laudatorio en nuestras letras, ya que cronológicamente comprende un amplio conjunto de textos que van desde Garcilaso de la Vega hasta un encomio tardío del conde de Torrepalma.

La presente colección de ensayos se inaugura con un brillante panorama general dedicado a los poemas neolatinos a bodas, firmado por el máximo especialista en la materia (A. Serrano Cueto). Seguidamente, entre los artículos aquí reunidos, varios trabajos se centran en dos de los principales nombres del Parnaso áureo: Garcilaso (R. Béhar) y Góngora (M. Blanco, J. Ponce Cárdenas). Otros estudiosos, en cambio, han optado por poner el foco en la obra de ingenios bien conocidos, pero cuya producción epitalámica todavía no se ha estudiado con suficiente detenimiento: Lupercio Leonardo de Argensola (J. Ignacio Díez), Gabriel Bocángel (J. Matas) y Gabriel de Corral (M. Jiménez). Por otro lado, resulta muy novedoso el rescate crítico de piezas nupciales de escritores hoy casi olvidados, como el aragonés Martín Miguel Navarro (I. Colón) o el luso Manoel de Galhegos (A. Plagnard). Finalmente, sobrepasando el límite del Siglo de Oro, hemos querido rastrear también las huellas de la escritura epitalámica en el siglo XVIII, atendiendo al testimonio lírico de la Invocación a Himeneo, que el conde de Torrepalma compuso en loor de los esponsales de la infanta María Teresa de Borbón con el Delfín de Francia en 1745 (L. Sánchez Laílla).

Albergamos la esperanza de que el fruto de este esfuerzo colectivo impulsado por un grupo de investigadores procedentes de diversas universidades francesas y españolas dé a conocer un género poético singularmente atractivo, preterido durante demasiado tiempo. Ojalá sirvan las páginas de este monográfico para asentar sobre cimientos firmes la recuperación de un destacable capítulo del patrimonio literario hispánico.

\section{Jesús Ponce Cárdenas Universidad Complutense de Madrid}

33. «A primera sang: batalles nupcials en la Catalunya barroca. Els epitalamis al galant Alba de Francesc Fontanella», Scripta, 10, 2017, p. 229-256.

34. «Poesía y linajes: los Aplausos poéticos de Ignacio de Luzán», La razón es Aurora. Estudios en Homenaje a la profesora Aurora Egido, Zaragoza, Institución Fernando el Católico, 2017, p. 483-500.

35. «Bodas reales entre Viena y Barcelona: un epitalamio latino de 1708», Liburna, 14, 2019, p. $143-154$. 